\title{
Denim Kumaşlarda Görüntü İşleme İle Hata Tespiti
}

\author{
Zeynep PINAR*, Fidan KAYA GÜLAĞIZ, Mehmet Ali ALTUNCU, Suhap ŞAHİN \\ Kocaeli Üniversitesi, Bilgisayar Mühendisliği Bölümü, Kocaeli \\ (ORCID: 0000-0001-7434-7697) (ORCID: 0000-0003-3519-9278) \\ (ORCID: 0000-0002-2948-3937) (ORCID: 0000-0003-1340-8972)
}

\begin{abstract}
$\ddot{O} \mathbf{z}$
Tekstil sektöründe, mamul kumaş üzerindeki üretim hatalarının tespiti, kalite kontrol aşamasında yapılan en önemli ve maliyetli işlerdendir. Kumaşlar konfeksiyon aşamasına gelmeden kontrol edilir ve hatalı kısımlar kumaşın içinden parça halinde kesilerek alınır. Bu durum fireye yani üretimde düşüşe yol açmaktadır. Eğer kontrol esnasında fark edilememiş veya parça alımı ile fireye ayırılamamış kusurlar varsa bu kumaşlarda ikinci kaliteye düşmektedir. Kalite kontrol sonrası top kesim işleminde ayrılan hatalı parça kumaşlar veya fark edilmeyerek müş̧eriye gönderilmiş ikinci kalite ürünler ciddi maliyetlere sebep olmaktadır. İnsan gözüyle yapılan kalite kontrol işlemi, iş gücü ve zaman olarak oldukça maliyetli olmasına rağmen başarımı istenildiği kadar yüksek değildir. Bu nedenle kalite kontrol aşamasında otomatik ve akıllı sistemlerin kullanımı için çalışmalar yapılmaktadır. $\mathrm{Bu}$ çalışmada, \%100 pamuk ipliğinden üretilerek ve indigo boyarmaddesi ile boyanmış olan denim kumaşlardaki hataların tespiti ve sınıflandırılması için görüntü işleme yöntemleri önerilmektedir. Yapılan çalışmada görüntü işleme algoritmaları kullanılarak hata tespiti yapılan kumaş görüntülerinden, özellik çıkarımı ile sayısal veri elde edilmiş̧ir. Oluşturulan özellik matrisi beş farklı algoritma kullanılarak incelenmiş, hatalı ve hatasız görüntünün ayrımı sağlanmıştır. Yapılan karşılaş̧ırmalarda en iyi performans gösteren algoritmanın J48 Karar Algoritması olduğu görülmüştür.
\end{abstract}

Anahtar kelimeler: Görüntü İşleme, Denim, Kalite Kontrol.

\section{Error Detection in Denim Fabrics with Image Processing}

\begin{abstract}
The textile industry is one of the most important and economical jobs in the quality control process for the detection of production defects in the production of finished fabrics. The fabrics are checked before they come to the garment process and the faulty parts are cut into pieces from the fabric. If there are any defects that cannot be noticed during the inspection or cannot be separated by waste cutting, this decreases the fabrics to second quality. After quality control, faulty piece fabrics separated in the cutting process or second quality products sent to the customer cause serious costs. Although the quality control process performed by the human eye is quite costly in terms of labor and time, its performance is not as high as desired. For this reason, studies are carried out for the use of automatic and intelligent systems in the quality control stage. In this study, image processing methods are proposed for the detection and classification of defects in denim fabrics produced from $100 \%$ cotton yarn and dyed with indigo dyestuff. Digital datas were acquired by feature extraction from fabric images which were detected by using image processing algorithms. Five different algorithms have been run on the feature matrix and distinction between the defective and clean image has been provided. According to the comparisons, it is concluded that the best performing algorithm is J48 Decision Algorithm.
\end{abstract}

Keywords: Image Processing, Denim, Quality Control.

\section{Giriş}

Tekstil sektöründe önemli bir sorun olan kumaş kalitesinin düşmesine birçok üretim hatası neden olsa da temel neden iplik hataları olarak görülebilir. Kumaş hataları ve hata puanlaması ile kalite sınıfları belirlenen kumaşların, düşük kalitede üretimleri maliyetleri ciddi derecede yükseltmektedir. Hali

*Sorumlu yazar: zeynep.pinar@guncelyazilim.com.tr

Geliş Tarihi: 23.07.2019, Kabul Tarihi: 22.03.2020 
hazırda, denim kumaş kalite kontrol işlemi 1şıklı kalite kontrol makinaları üzerinden akan kumaştaki hataları, göz taraması ile kontrol eden personeller tarafından yapılmaktadır [1].

Kumaş hataları literatürde 200'ün üzerinde tanımlanmaktadır, fakat pratikte 40-50 kadarı kalite kontrol kartlarına işlenmektedir [2]. Bu nedenle hataların sıklığı ve türleri geniş bir zaman aralığında takip edilmelidir. Denim işletmelerinde mamul kumaş elde edilirken, iplikten kalite kontrol aşamasına kadar olan süreçte çeşitli sebeplerden kumaş hataları oluşmaktadır.

Kumaş hataları giyim endüstrisindeki hataların \%85'ini oluşturmaktadır. Bu hataların \%70'ini belirleyebilen bir kalite kontrol elemanın eğitimi, zaman ve maliyet açısından oldukça zahmetlidir. Dolayısıyla kalite kontrol sürecindeki otomatik sistemler maliyeti düşürürken kaliteyi artırmaktadır [2]. EVS ve Zelleweger Uster firmaları, eğitilmiş bir kalite kontrol elemanının kumaş kontrolünde ancak hataların \%40-60 arasında tespit edebildiğini ifade etmektedir. İyi bir kumaş kontrolcüsünün yetişmesi yıllar sürerken, otomatik kontrol sistemlerin kurulması ve çalıştırılması birkaç hafta almaktadır [3]. Gözle hata tespitinde, operatörün dikkat dağınıklığı, değerlendirmenin objektifliği, işlem zamanı ve uzun vadede kalitesizliğin maliyete olan etkileri gibi sebepler ele alındığında otomatik sistemlerin geliştirilme çalışmalarının sürdürülmesi gerekmektedir [1].

\subsection{Literatür İncelemesi}

Kumaş resimleri üzerinde hata sınıflandırması yapılan bir çalışmada, temel bileşenler analizi (PCA) ve yapay sinir ağı (YSA) tabanlı yöntemler MATLAB'da kodlanarak, dört adet hata grubuna ait görüntüler için sınıflandırma başarısı test dilmiş ve sırası ile \%66-\%100 oranında başarı elde edilmiştir [4]. Kumaş görüntüsünden hata analizine ait başka bir çalışmada, görüntü işleme yöntemleri uygulanmış ve şekilsel, histogram özellikleri çıkartılmıştır. Bu özellikler Fuzzy C-Means algoritması ile kümelenmiştir. Daha sonra Fourier Analizi, Gabor Filter ve Dalgacık Dönüşümü Yöntemleri karşılaştırılmış ve en iyi sonuç Fourier tabanlı görüntü işleme yönteminden alınmıştır [5]. Kumaş ile karışmış olabilecek kusurlu iplikler, renk ve gözenek eşitsizliği, gibi sebeplerden oluşan hataların tespiti için, filtrelere dayalı bir yöntem olarak Gabor dalgacık ağı ile doku farklılıkları elde edilmiştir [6]. Gerçek zamanlı olarak yapılan bir çalışmada, eksik iplikler, yağ lekeleri ve delik hatalarının tespitinde yapay sinir ağları önerilmiştir [7]. Dokuma kumaş bloklarının tüm kumaş görüntüsünden ayıklanması amacıyla Gauss bulanıklığı, Kinsan-bilgisayar etkileşimi ile kümeleme ve maksimizasyon algoritmaları uygulanmış bir çalışmada kullanılan algoritmaların düzensiz yapı alanına sahip, karmaşık kumaş görüntüsünde daha verimli ve doğru çalışmakta olduğu belirtilmiştir [8]. Yuvarlak örgü makinesi üzerinde gerçek zamanlı çalışan kumaş hata tespit sisteminde, GDF-HOG, Eig(Hess)-HOG, ikinci mertebe HOG, Eig(Hess)-CoHOG, GM-CoHOG ve yüzey etiketleme temelli CoHOG olmak üzere 6 yeni öznitelik çıkarım algoritması oluşturulmuş ve bunlara ek olarak Fourier, Dalgacık ve Shearlet dönüşüm yöntemleri kullanılarak spektral kumaş görüntülerinin belirli istatistiksel öznitelikleri çıkartılarak sınıflandırılmaları sağlanmıştır. Uzaysal alanda GM-CoHOG algoritmasının en yüksek sınıflandırma başarısına sahip olduğu sonucuna varılmıştır [9]. Kumaş öznitelikleri çıkartılarak elde edilen taslak ile test örneklerinin frekans alanında basit şekilde karşılaştırılmasında online ve tamamen optimize edilmiş gerçek zamanlı bir hata tespit sisteminde kullanılacak en iyi yöntemin Fourier Dönüşümü olduğu belirtilmiştir [10]. Biyolojik olarak insan gözünden esinlenerek oluşturulmuş bir bilgisayar sistemi olan yapay görmenin kumaş kusurlarını bulmada hangi aşamalarda kullanılabileceğini araştıran bir başka çalışmada, kumaş hatalarının tümünü tespit edebilen bir yapıya rastlanmamıştır. Yaklaşımların test sonuçlarının istenen düzeyde olmadığı, tespit oranının yüksek olduğunda da maliyetlerin fazlalaştığ bu alanda çalışmaların devam etmesine vurgu yapılmıştır [11].

Bu çalışmada, denim kumaş kalite kontrolü sırasında en çok rastlanan hata gruplarından [2] alınan kumaş görüntülerinin hatalı ve hatasız olarak ayrılmasında, sınıflandırma ve karar algoritmalarından en iyi performansa sahip olanın tespit edilmesi amaçlanmıştır. Kumaş hataları öncelikle ağırlık toplama yöntemi ile gri seviyeye dönüştürülmüş ve histogram eşitleme ile hataların daha belirgin görülmesi sağlanmıştır. Hatalı ve hatasız görüntüler üzerinde fourier analizi yapılarak, fourier spektrumu ile kumaş hatalarına ait $p_{1}, p_{2}, p_{3}, p_{4}, p_{5}, p_{6}$ olacak şekilde altı adet özellik çıkartılmıştır. Oluşturulan özellik vektörleri K-Means, J48, Lineer Regresyon, Naïve Bayes ve DFF Neural Network (Derin İleri Beslemeli Sinir Ağı) algoritmalarına verilerek performans karşılaştırması yapılmıştır. 
Gerçekleştirilen çalışmanın ileride ürüne dönüştürülebilmesi açısından, kullanılan yöntemler Phyton dili kullanılarak kodlanmıştır. Literatürde kalite kontrol aşamasında hata tespiti yapan sistemlerden, ürüne dönüştürülmüş Cyclops kontrol sistemi, Elbit Vision I-Tex kontrol sistemi ve Uster Fabricscan kontrol sistemlerinin manuel hata tespit yöntemleri ile karşılaştırılması üzerine çalışmalar yapılmış avantaj ve dezavantajları ortaya koyulmuştur [1]. Cyclops kontrol sistemi hata tespitinde yüzde 70 başarı sağlayarak dokuma tezgâhı üzerinde çalışmakta ve sadece ham kalite kontrol aşamasında kullanılmaktadır. Elbit Vision I-Tex kontrol sistemi denim kumaşlarda kullanılabilmekte ancak 15 adet hata tipi üzerinde saptama yapabilmektedir. Uster Fabricscan kontrol sistemi birçok kumaş çeşidinde hata tespiti yapabilmektedir. Ancak tarama hızı daha düşük, kendi kumaş taşıma ünitesini içeren ek makine ve yüksek işçilik gereksinimleri sebebi ile de kullanışlı olmamakla beraber yüksek maliyet gerektirmektedir. Aynı zamanda EVS ve Zelleweger Uster firmaları tarafından geliştirilmiş otomatik sistemler hata tespitini farklı kumaş tipleri için \%80-95 başarı ile yapabilmektedir. Tüm bu örnekler göz önünde bulundurulduğunda önermekte olduğumuz hata tespit sisteminin başarısının yüzde 87 oranında olması, 20 çeşit farklı hata içeren veri seti içerisinde hatalı kumaşları tespit edebilmesi ve maliyetli bir ek donanım gerektirmemesi sebebiyle ileride yapılacak ürüne dönüştürme süreçlerine kaynak sağlamaktadır.

\subsection{Denim Kumaş Hataları}

Atk1 ve çözgü ipliklerinin dik açı ve örgü teknikleri ile bir düzen içerisinde birleştirilerek dokuma tezgahlarında tekstil yüzeyi meydana getirilmektedir. Atkısı boyanmamış ham pamuk ipliği ile çözgü iplikleri bir araya gelerek denim kumaş yapısı oluşmaktadır [12]. Denim kumaş yapısını diğer kumaşlardan ayıran özelliği çözgü ipliklerinin indigo boyarmaddesi ile boyanmış olmasıdır [13]. Bu nedenle denim kumaşların kalite standartlarını etkileyen temel sebepler; atkı ve çözgü ipliklerinin özellikleri, dayanıklılığı, kopuş oranları ve dokuma makinesinin duruşlarıdır.

Sık görülen atkı ve çözgü hataları;

- yarım atk1,

- yarım atkı kaçı̆̆ı,

- atkı kaçı̆̆ 1 ,

- çift atk1,

- atk1 yığması,

- çift çözgü,

- çözgü kopuğu,

- çözgü yığmas1,

- çözgü kaçığı olarak hata kartlarına işlenmektedir [14].

Dokuma hata sayılarının istatistiksel olarak incelendiği bir çalışmada, 1şıklı kontrol panosu aracılığı ile tespit edilen 28 dokuma hatası arasından, çözgünün ipliğindeki kopuştan dolayı meydana gelen ve kumaşın boyunca devam eden çözgü kopuğu hatasının \%48.02 oranla en yoğun görülen hata çeşidi olduğu belirtilmiştir. Çözgü kopuğu, çözgünün ipliğindeki kopuştan dolayı meydana gelen ve kumaşın boyunca devam eden bir hatadır. Bir başka sık rastlanan hata, atkı yığılması, atkı ipinin düzgünsüzlüğü veya sıklığından meydana gelmektedir [2].

\section{Materyal ve Metot}

$\mathrm{Bu}$ çalışmada tekstil sektöründeki kalite kontrolünde hata ayrımı için en iyi performansa sahip algoritmalar üzerine araştırmalar yapılmıştır. Denim üretimi yapılan bir işletmeden, farklı hata gruplarına ait 52 adet hatalı ve 25 adet hatasız kumaş görüntüsü elde edilmiştir. Bu görüntüler atk1 kaçığı, çözgü kaçığı, pamuklama, duruş izi vb. olmak üzere 20 çeşit hata içermektedir. Toplamda 77 adet görüntü bu çalışma için veri tabanı olarak kullanılmıştır. Hata tespiti için öncelikle görüntü işleme yöntemlerinden faydalanarak hatanın görüntüden ayırt edilmesi üzerine algoritmalar kodlanmıştır. Kodlanmış olan algoritmalar aşağıda türlerine göre listelenmiştir.

Hata tespiti için kullanılacak algoritmalar;

1. Ağırlık Toplama

2. Histogram Eşitleme 


\section{Fourier Analizi}

Hatalı ve hatasız görüntülerin ayrımında kullanılacak algoritmalar;

1. K-means Algoritmas1

2. J48 Karar Algoritmas1

3. Lineer Regresyon

4. Naive Bayes Algoritması

5. DFF Neural Network

olarak belirlenmiștir.

\subsection{A ğırlık Toplama}

Görüntü işlemede kullanılan renkli bir başka adıyla RGB (Red, Green, Blue) resimlerin griye dönüştürülmesi diğer algoritmaların çalıştırılması için kolaylık sağlamaktadır. Dolayısıyla genellikle griye dönüştürülmüş resim üzerinden görüntü işleme yapılmaktadır. Ağırlık toplama ile griye dönüştürme yönteminde R, G, B kanallarının kendine özgü ağırlıkları uygulanmaktadır. Sırasıyla R, G, B kanallarının ağırlıkları; 0,2126 - 0,7152 - 0,0722 'dir. Griye dönüştürme işleminde görüntü piksel piksel ele alınmaktadır. Buna göre;

$$
Y=\frac{1}{3}(R+G+B)
$$

denkleminde renkli görüntünün kırmızı, yeşil ve mavi bileşenlerinin aritmetik ortalaması alınarak, eşitlik (2) ile hesaplanmaktadır [15].

$$
Y=0,2989 R+0,5870 G+0,1140 B
$$

\subsection{Histogram Eşitleme}

Düşük işlem maliyeti ve yüksek çalışma performansı sayesinde histogram eşitleme metodu hata tespiti yapılacak görüntülerde kullanılmaktadır. Aynı zamanda griye dönüştürülmüş görüntüler hakkındaki piksel bilgisini veren en iyi yöntemlerden olarak kabul edilmektedir [16].

Histogram kavramı, görüntünün içerdiği piksel değerlerinin ağırlı̆̆ını belirten grafiksel bir gösterimdir. Görüntü islemede histogramlar kullanılarak resim daha belirgin hâle getirilebilir. Daha net bir görüntü için histogramın daha ayrık ve düzgün bir yapıya gelmesi sağlanmalıdır. $g_{0}, g_{1}, \ldots, g_{L-1}$ gri değerlerine sahip bir dijital görüntünün histogramı için (3) denklemindeki ayrık fonksiyon tanımlanmaktadır;

$$
p\left(g_{k}\right)=\frac{n_{k}}{n}
$$

$n_{k}$ : gri değere sahip piksellerin toplam sayıs1

$n$ : görüntüdeki toplam piksel sayıs1

Histogram, dijital bir görüntüde genel bir tanım görünümü elde edilmesini sağlamaktadır. Bir görüntünün gri değerlerini rastgele bir değişken olan $\mathrm{R}$ varsayılırsa histogram tahmini bir olasılık yoğunluğu verir. Başka bir deyişle eşitlik (4) olarak ifade edilmektedir.

$$
P\left(R=g_{k}\right) \sim p\left(g_{k}\right)
$$
1 olmaktadır.

$\mathrm{Bu}$ durumda histogram eşitlenmiş bir görüntüdeki gri değerli piksellerin toplam olasıllık değeri

\subsection{Fourier Analizi}

Herhangi bir sinyalin sinüs ve kosinüs dalgalarının çeşitli genlik ve frekanslarla toplamından elde edilebileceğini Fourier teoremi açıklamaktadır. Görüntü uzayındaki tekrarlı ve düzenli desene sahip 
kumaşlar ile uzaysal frekanstaki spektrumları arasındaki ilişki, iki boyutlu Fourier dönüşümü kullanılarak kurgulanmaktadır. $\quad N \times N$ iki boyutlu bir $f(x, y)$ görüntüsü için, $x, y$ uzaysal koordinatlarında gri seviyeyi temsil etsin. Bu durumda $F(n, m)$ ayrık fourier dönüşümüne karş1lık gelen genel denklem (5)'deki gibidir.

$$
F(n, m)=\frac{1}{N^{2}} \sum_{y=0}^{N-1} \sum_{x=0}^{N-1} f(x, y) \times e^{-\frac{j 2 \pi(x n+y m)}{N}}
$$

Görüntü işleme ile hata tespitinde griye çevirme ve histogram eşitleme ile basite indirgenmiş resimde öznitelik çıkarımı yapılmaktadır. Öznitelik çıkarım metotları dört yaklaşım ile ele alınmaktadır. Bunlar; istatistiksel yaklaşımlar, spektral yaklaşımlar, model tabanlı yaklaşımlar ve yapısal yaklaşımlardır [17]. Spektral yaklaşımlarda görüntünün, uzaysal domaindeki gri seviye değerleri Gabor filtreleme, Fourier dönüşümü ve Dalgacık dönüşümü gibi işlemler ile farklı domainlere dönüştürülür. Elde edilen bu bilgiler öznitelik çıkarımı yapılarak sınıflandırma algoritmaları için girdi olarak alınmaktadır [16].

\subsection{K-Means Algoritması}

Kullanılan en yaygın kümeleme algoritmalarından biri olan K-means algoritması her verinin sadece bir kümeye dâhil olabilmesine izin vermektedir [18]. K-means algoritması için öncelikle verinin kaç kümeye bölüneceği belirlenir. Oluşturulacak kümelerin kendi içlerinde benzerlikleri yüksek ve kümeler arasındaki benzerliğin düşük olması hedeflenmektedir. Küme içi benzerlik kümedeki verilerin ortalama değeri ile ölçülmektedir ve bu da kümenin ağırlık merkezidir. K-means algoritması $\mathrm{n}$ tane nesneyi k adet kümeye bölmektedir [19]. K-means algoritmasının uygulama adımları dört adımda özetlenmektedir;

1.Adım: Veriler uygun k adet kümeye bölünür; $\left\{C_{1}, C_{2}, \ldots, C_{k}\right\}$

2.Adım: Küme merkezleri hesaplanır;

$$
w_{i}=\frac{1}{K_{i}} \sum_{j=1}^{K_{i}} w_{i j}, \quad i=1,2, \ldots, K
$$

3.Adım: Bulunan her bir küme merkezi $w_{i}$ için ;

3.1. Adım: Tüm nesnelerin merkeze olan uzaklıkları denklem (7) ile hesaplanır.

$$
\left\|w_{i}-\overline{w_{t}}\right\| \leq\left\|w_{i}-\overline{w_{J}}\right\|, j=1, \ldots, K, \quad j \neq s
$$

3.2.Adım: Elde edilen sonuca göre her nesne $\mathrm{k}$ adet kümeden kendilerine en yakın olan kümeye yerleştirilir.

4.Adım: Küme merkezleri stabilize olana kadar 2. ve 3.adımlar tekrar edilir [20].

\subsection{J48 Karar Algoritması}

J48 bir karar ağacı algoritmasıdır ve öznitelik vektörünün çeşitli durumlar için davranış şeklini tespit etmektedir. Algoritma hedef değişkenin tahmini için kurallar oluşturur. Elde edilen kural ağacı ile verilerin sinıflandırılması kolaylıkla yapılabilir duruma gelir [21].

Karar ağacı oluşturma süreci temelde ağaç oluşturma ve ağaç budama olarak iki basamaktan oluşmaktadır. Ağaç oluşturmada, kök düğümünden başlayarak her yinelemede seçilecek niteliğe göre farklı dallar oluşur. Ayrım yapacak nitelik kalmayana kadar bu süreç devam eder. Düğümlerdeki nesneler ne kadar homojen dağılırsa dallanma yapısı o kadar verimli olacaktır [22]. J48 karar ağac1 algoritmasının sözde kodu aşağıdaki gibidir [23].

Adım 1: MaxBilgi değişkenini sıfira eşitle.

Adım 2: Güncel veri setinin entropisini hesapla. 
Adım 3: FOR veri setindeki her bir özelik

3.1. Güncel veri setindeki özelliklerden bir tanesini seç.

3.2. Seçilen özellik için bilgi değerini hesapla.

3.3. Seçilen özellik için bilgi kazanımını hesapla.

3.4. IF bilgi kazanımı > MaxBilgi then

3.4.1. MaxBilgi değişkenine bilgi kazanımı değerini ata.

Adım 5: END FOR

Adım 6: MaxBilgi değerine sahip özelliği ağaca ekle.

Adım 7: MaxBilgi değerine sahip özeliği veri setinden sil.

Adım 8: Until veri setindeki özellik sayısı $=0$

Adım 9: Bitir

\subsection{Lineer Regresyon}

Lineer regresyon, iki sayısal değer arasındaki ilişkiyi özetler. Doğrusal bir lineer regresyon modeli denklem (8) ile yazılmaktadır.

$$
y=a+b x+\varepsilon
$$

$x$ : bağımsı değişken

$y:$ bağımlı değişken

$a:$ kesişim noktas1

$b$ :ĕgim

$\varepsilon$ : rastsal hata

Regresyon modelini oluşturmada en yaygın kullanılan yöntem en küçük kareler yöntemidir. $\mathrm{Bu}$ sayede her veri noktasının lineer denklem doğrusuna olan dik uzaklıkları hesaplanarak minimize edilir ve böylece daha doğru modelin kurulması sağlanır [24].

\subsection{Naive Bayes Sınıflandırma}

Veri madenciliği ve örüntü tanıma gibi alanlarda yaygın olarak kullanılan sınıflandırma yöntemlerinden biri olan Naïve Bayes, koşullu olasılıklar arasında bağıntı kuran Bayes teoremine dayanmaktadır [25].

Veri setindeki her bir örnek $X=\left\{x_{1}, x_{2}, \ldots, x_{n}\right\}$ değerlerinden oluştuğunda toplam $\mathrm{n}$ tane sınıf oluşursa sınıfı belirlemek için (9) olasılık denklemi kullanılır [26].

$$
P\left(C_{i} \mid X\right)=\frac{P\left(C_{i} \mid X\right) P\left(C_{i}\right)}{P(X)}
$$

$X$ : sinıflandırılacak veri seti

$C:$ sinif sayis 1

$P$ : olasilık değeri

Hesaplamadaki $X_{i}$ değerleri birbirinden bağımsız olarak alınır ve payda değerlerinin eşit olduğu bilindiğinden, $P\left(C_{i} \mid X\right)$ içinde pay değerleri karşılaştırılır. En büyük pay değeri seçilerek bilinmeyenin hangi sinıfa ait olduğu belirlenir [27].

\subsection{Derin İleri Beslemeli Sinir Ăğ (Deep Feedforward Neural Network-DFF)}

Derin ileri beslemeli sinir ağı, bir ileri beslemeli yapay sinir ağı sınıfıdır. DFF, en az üç düğüm katmanından oluşur (Şekil 1). Giriş düğümleri haricinde, her düğüm doğrusal olmayan bir etkinleştirme işlevi kullanan bir nörondur. DFF, eğitim için geri yayılım (backpropagation) olarak adlandırılan denetimli bir öğrenme tekniğini kullanır. Çok tabakalı ve lineer olmayan aktivasyon, DFF'yi doğrusal bir algılayıcıdan ayırır. Doğrusal olarak ayrılabilir olmayan verileri ayırt edebilir [28]. 


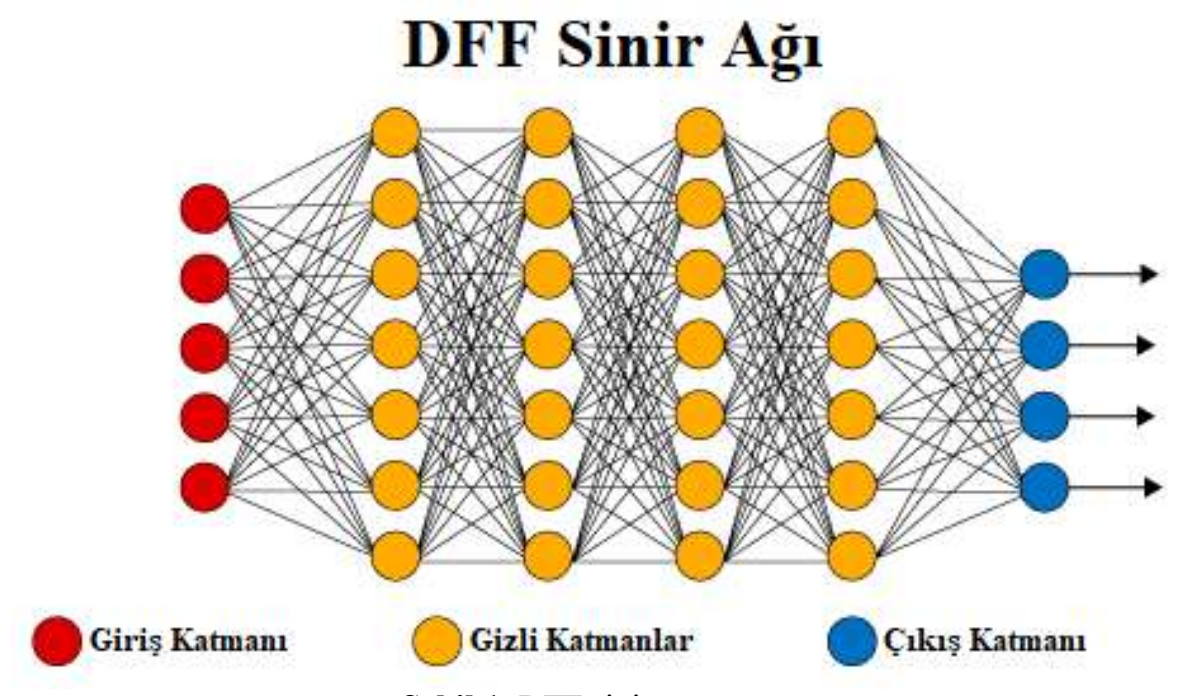

Şekil 1. DFF sinir ağı yapısı

DFF'de sinir ağına ait veriler aşağıdaki adımlarla hesaplanmaktadır [29].

Adım 1: Giriş değerleri daha önce belirlenmiş ağırlık değerleriyle (w) çarpılır.

Adım 2: Adım 1'de elde edilen değer ile bias (b) değeri ile toplanır. w ve b parametreleri çıktı sonucunu en iyi verecek şekilde her eğitim adımında (epoch) değiştirilmektedir.

Adım 3: Çıkış fonksiyonunun doğrusal fonksiyon gibi davranmaması için aktivasyon fonksiyonuna tabi tutulur. Buradaki amaç ise sinir ağının öğrenme gücünü arttırmaktadır.

Çalışmada modellenen DFF sinir ağına ait parametreler Tablo 1'de verilmiştir.

Tablo 1. DFF sinir ağı parametreleri

\begin{tabular}{ll}
\hline Giriş Katmanı Hücre Sayıs1 & 6 \\
Gizli Katman Sayısı & 3 \\
Gizli Katman Hücre Sayıları & $10,8,12$ \\
Gizli Katmanda Kullanılan & ReLu, ReLu, Sigmoid \\
Aktivasyon Fonksiyonları & \\
Çıkış Katmanı Hücre Sayısı & 1 \\
Optimizer & Adamax \\
Batch_Size & 8 \\
Test Size & 0,10 \\
\hline
\end{tabular}

\section{Bulgular ve Tartışma}

\subsection{Görüntülerin Elde Edilmesi}

Bu çalışmada kullanılmak üzere 52 adet hatalı, 25 adet temiz olmak üzere toplamda 77 adet; farklı renk, örgü tipine sahip kumaş görüntüsü 3872×2592 çözünürlükte çekilmiştir. Elde edilen görüntüler JPEG formatında kaydedilmiş ve görüntü işleme yöntemleri uygulanmıştır.

\subsection{Görüntü İşleme Yöntemleri ve Özellik Matrisinin Elde Edilmesi}

Hatalı ve hatasız kumaşlardan elde edilen görüntü kümesi kodlanmış görüntü işleme algoritmalarından geçirilerek Fourier analizi ile hata grafikleri elde edilmiştir. Yapılan çalışmanın genel iş akışı Şekil 2' de gösterilmiştir. 


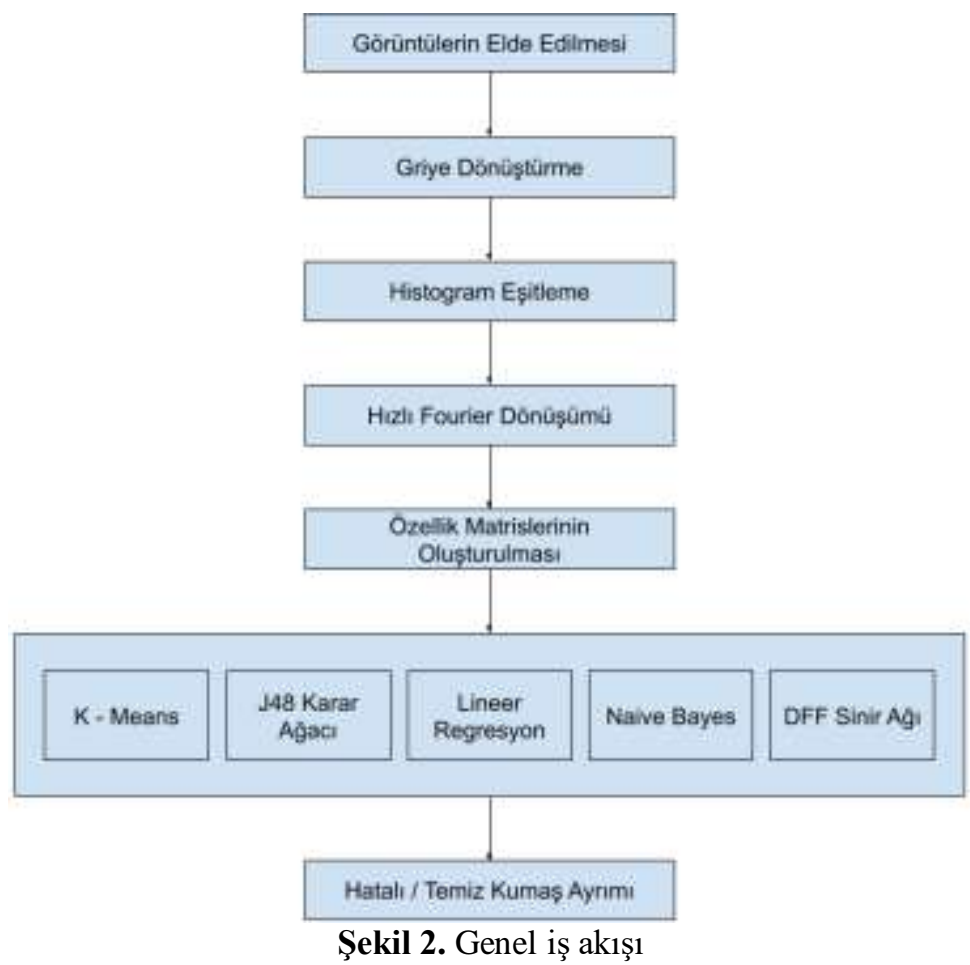

Fourier analizinde elde edilen görüntü grafiklerinde hatalı kumaşlardaki grafik kırılımları ve en yüksek tepe değeri alınarak öznitelik matrisi çıkarılmıştır.

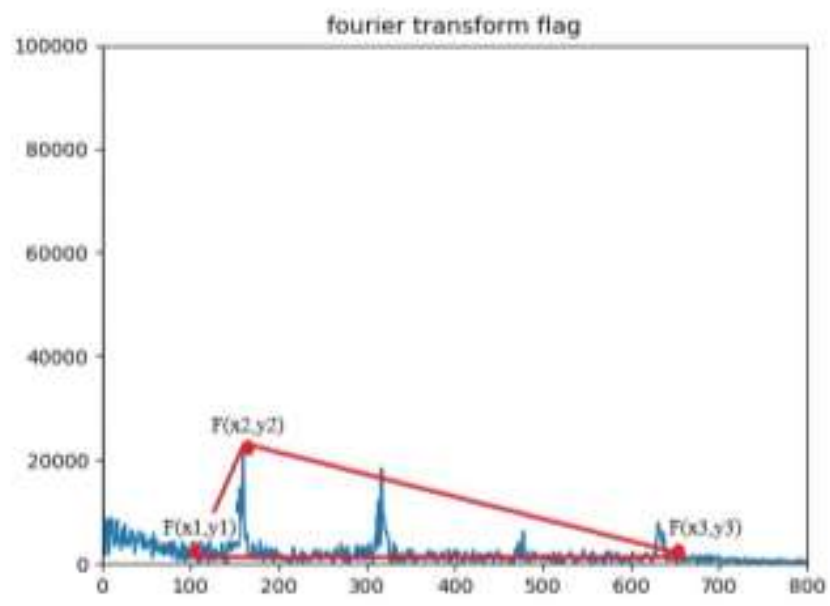

Şekil 3. Hatalı Kumaş Fourier Grafiği

Gri seviyedeki görüntüyü büyüklük ve faza dönüştürmek için hızlı Fourier dönüşümü kullanılmaktadır [30]. Görüntünün Fourier spektrumu kumaşın örgü tekniğinden etkilenmez iken dokusundaki farklılıklarda kıvrım yapmaktadır [16]. İncelenen 77 adet kumaş görüntüsünde hatalı görüntülerin Fourier spektrumu simetrik kıvrımlar yaparken, hatasız kumaş görüntülerinde kıvrım tek tepe değerli veya tek düze ilerlediği saptanmıştır. Buna göre Şekil 3'te ara hatasının görüldüğü denim kumaş görüntüsünün Fourier grafiği örneklenmiştir. Burada;

$F_{i}\left(x_{1}, y_{1}\right):$ Hata başlangıç değeri

$F_{t}\left(x_{2}, y_{2}\right):$ Hata tepe noktas 1

$F_{S}\left(x_{3}, y_{3}\right)$ : Hata bitiş değeri olarak alınmıştır.

Buna göre öznitelik matrisi için denklem (10) eşitlikleri hesaplanmıştır.

$p_{1}=\left|F_{i} F_{t}\right|$ 


$$
\begin{aligned}
& p_{2}=\left|F_{t} F_{s}\right| \\
& p_{3}=\left|F_{i} F_{s}\right| \\
& p_{4}=\frac{p_{1}}{p_{2}} \\
& p_{5}=\frac{p_{2}}{p_{3}} \\
& p_{6}=\frac{p_{1}}{p_{3}}
\end{aligned}
$$

Hatalı görüntüler için " $\mathrm{H}$ ”, hatasız görüntüler için " $\mathrm{T}$ ” sınıf etiketleri verilerek; $M=\left[p_{1}, p_{2}, p_{3}, p_{4}, p_{5}, p_{6}, H\right]$ özellik vektörü oluşturulmuştur. Her bir görüntü için oluşturulan bu vektörler ile $(77 \times 7)$ boyutunda özellik matrisi elde edilmiştir ve K-means, lineer regresyon, J48 karar ağacı, Naive Bayes, DFF Neural Network algoritmalarına girdi olarak verilmiş hatalı-hatasız ayrımının yapılması sağlanmıştır. Buna göre bir görüntünün tüm aşamaları Tablo 2.' de gösterilmiştir.

Tablo 2. Hatalı ve hatasız görüntünün işlenme aşamaları

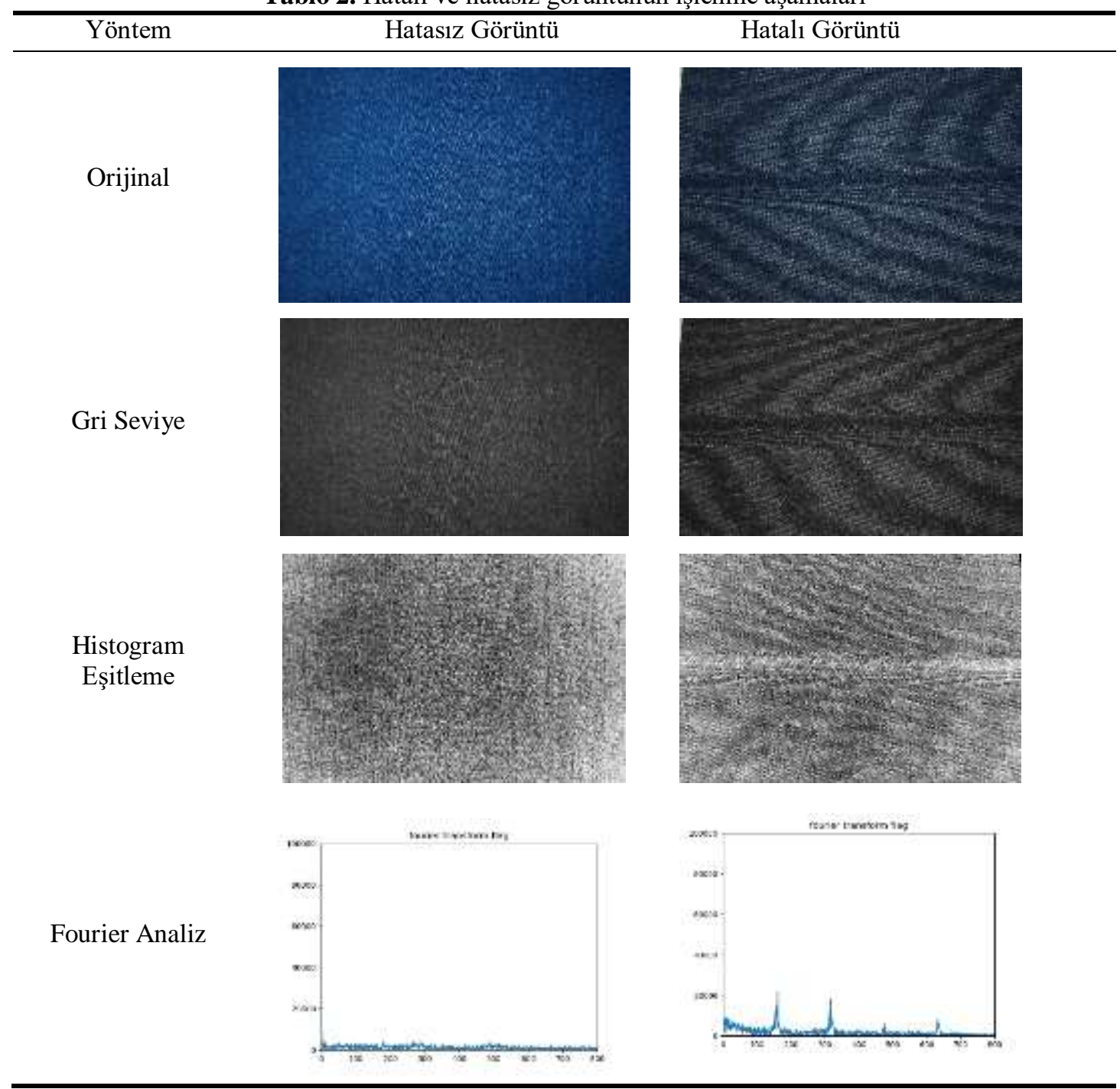

Özellik değerleri elde edildikten sonra her görüntüye ait altı özellik kullanılarak sınıflandırma işlemi gerçekleştirilmiştir. Lineer Regresyon, Naive Bayes, DFF Sinir Ağı ve J48 yöntemlerinde 10 katlı çapraz doğrulama kullanılarak sonuçlar hesaplanmıştır. K Means yönteminde ise sınıf etiketleri 
kullanılarak kümelerin değerlendirilmesi gerçekleştirilmiştir. Sınıflandırma işlemine ait elde edilen sonuçlar Tablo 3'de gösterilmiştir. Tablo 3'de yer alan sonuçlar doğrultusunda en düşük hata değerinin J48 yöntemiyle elde edildiği tespit edilmiştir.

Tablo 3. Sinıflandırma yöntemlerine ait hata oranları

\begin{tabular}{ccc}
\hline \multicolumn{3}{c}{ Sinıflandırma } \\
\hline & RMSE & Doğruluk Yüzdesi \\
Linear Regression & 3,8626 & - \\
Navie Bayes & 0,4032 & $\% 83,12$ \\
DFF Neural Network & 0,3646 & $\% 85,71$ \\
$\mathbf{J 4 8}$ & $\mathbf{0 , 3 4 4 8}$ & $\mathbf{\% 8 7 , 0 1}$ \\
\hline
\end{tabular}

Sınıflandırma ve kümeleme işlemleri farklı teknikler olduğundan yöntemlerin değerlendirme kriterleri de farklılık göstermektedir. Hatalı kumaşların tespiti için K Means kümeleme algoritmasına ait elde edilen hata değerleri Tablo 4'te gösterilmiştir. Doğruluk yüzdeleri bakımından sınıflandırma ve $\mathrm{K}$ Means kümeleme yöntemi karşılaştırıldığında denim kumaş hatalarının tespitinde sınıflandırma yöntemlerinin daha başarılı olduğu görülmüştür.

Tablo 4. Kümeleme yöntemine ait hata oranları

\begin{tabular}{ccc}
\hline \multicolumn{2}{c}{ Kümeleme } \\
\hline & & Küme İçi Hata Karelerinin \\
K Means & Doğruluk Yüzdesi & Toplamı \\
\hline
\end{tabular}

Hem kümeleme hem de sinıflandırma yöntemleri genel olarak karşılaştırıldığında yine J48 algoritması en doğru sonuçları üretmiştir. Tablo 5'te J48 algoritmasına ait karmaşıklık matrisi verilmiştir. Yöntemin yüzde 87 doğruluk oranı ile hataları tespit ettiği görülmektedir.

Tablo 5. J48 yöntemine ait doğruluk değerleri

\begin{tabular}{|c|c|c|c|c|c|c|c|}
\hline \multicolumn{8}{|c|}{$\mathrm{J} 48$} \\
\hline \multicolumn{8}{|c|}{ Karmaşıklık Matrisi } \\
\hline \multicolumn{8}{|c|}{ Gerçek Değer } \\
\hline \multirow{3}{*}{ 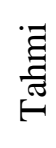 } & & $\mathrm{H}$ & $\mathrm{T}$ & Precision & Recall & F-Measure & Sinif \\
\hline & $\mathrm{H}$ & 46 & 4 & 0,920 & 0,885 & 0,902 & $\mathrm{H}$ \\
\hline & $\mathrm{T}$ & 6 & 21 & 0,778 & 0,840 & 0,808 & $\mathrm{~T}$ \\
\hline
\end{tabular}

J48 yönteminden sonra en başarılı sonuçları veren yöntem DFF Neural Network yöntemi olmuştur. DFF Neural Network yöntemine ait elde edilen karmaşıklık matrisi Tablo 6' da gösterilmiştir.

Tablo 6. DFF Neural Network yöntemine ait doğruluk değerleri

\begin{tabular}{|c|c|c|c|c|c|c|c|}
\hline \multicolumn{8}{|c|}{ DFF Neural Network } \\
\hline \multicolumn{8}{|c|}{ Karmaşıklık Matrisi } \\
\hline \multicolumn{8}{|c|}{ Gerçek Değer } \\
\hline \multirow{3}{*}{\begin{tabular}{l}
$\cdot \Xi$ \\
$\frac{\Xi}{\sigma}$ \\
\multirow{H}{*}{}
\end{tabular}} & & $\mathrm{H}$ & $\mathrm{T}$ & Precision & Recall & F-Measure & Sinif \\
\hline & $\mathrm{H}$ & 47 & 6 & 0,887 & 0,904 & 0,895 & $\mathrm{H}$ \\
\hline & $\mathrm{T}$ & 5 & 19 & 0,792 & 0,76 & 0,776 & $\mathrm{~T}$ \\
\hline
\end{tabular}

DFF Neural Network bir derin öğrenme yöntemidir ve genel olarak klasik sınıflandırma / yapay sinir ağları tekniklerine göre daha başarılıdır. Ancak çalışmamızda kullanılan veri seti üzerinde J48 yöntemi DFF Neural Network Yönteminden daha başarılı sonuçlar üretmiştir. DFF Neural Network yönteminin daha başarısız olmasında en temel etken veri setinin sınırlı sayıda veri içermesidir. Derin 
öğrenme yöntemlerinde veri sayısının başarı üzerindeki etkisi daha önceki çalışmalarda da [31] gösterilmiştir. Veri sayısının sınırlı olması nedeniyle öğrenme tam olarak gerçekleştirilememiştir.

\section{Sonuç ve Öneriler}

Bu çalışmada, denim kumaşlardaki hataların tespiti ve sınıflandırılması için görüntü işleme yöntemleri kullanılarak 77 denim kumaşa ait görüntüden altı farklı özellik çıkarılmıştır. Elde edilen özellikler kullanılarak sınıflandırma ve kümeleme yöntemleri üzerinden veri seti içerisindeki hatalı kumaşların tespiti sağlanmıştır.

Çalışma sonunda denim kumaşlardaki hata tespiti için sınıflandırma yöntemlerinin kümeleme yöntemlerinden daha doğru sonuçlar ürettiği tespit edilmiştir. Aynı zamanda sınıflandırma yöntemleri kendi içerisinde karşılaștırıldığında J48 algoritmasının DFF Sinir Ağı, Naive Bayes ve Lineer Regresyon yöntemlerine göre denim kumaşlarda hata tespiti için daha uygun olduğu tespit edilmiştir. İleriki çalışmalarda farklı özellik indirgeme teknikleri kullanılarak denim kumaşlardaki hata tespit oranının arttırılması hedeflenmektedir.

\section{Teşekkür}

Bu çalışma esnasında, görüntü toplama işlemi için desteklerinden dolayı Güncel Yazılım firmasına ve çalışanlarına teşekkür ederiz.

\section{Yazarların Katkısı}

Zeynep PINAR kavramsallaştırma, araştırma, algoritma kodlama, yazma ve düzenleme; Fidan KAYA GÜLAĞIZ araştırma, algoritma kodlama, yazma ve düzenleme; Mehmet Ali ALTUNCU araştırma, inceleme, yazma ve düzenleme; Suhap ŞAHIN denetim, inceleme ve gözden geçirme konularında katkı sağlamıştır.

\section{Çıkar Çatışması Beyanı}

Yazarlar arasında herhangi bir çıkar çatışması bulunmamaktadır.

\section{Araştırma ve Yayın Etiği Beyanı}

Yapılan çalışmada araştırma ve yayın etiğine uyulmuştur.

\section{Kaynaklar}

[1] Kısaoğlu Ö. 2006. Kumaş Kalite Kontrol Sistemleri. Pamukkale Üniversitesi Mühendislik Bilimleri Dergisi, 12 (2): 233-241.

[2] Ala D.M., İkiz Y. 2015. Dokuma Üretimi Süresince Oluşan Dokuma Hatalarının Belirlenmesine Yönelik İstatistiksel Bir Araştırma. Pamukkale Üniversitesi Mühendislik Bilimleri Dergisi, 21 (7): 282-287.

[3] Dorrity L., Vachtsevanos G., Jasper W. 1995. Real-Time Fabric Defect Defection \&Control in Weaving Processes. National Textile Center, G94- 2: 143-152.

[4] Büyükkabasakal K. 2010. Kumaş Dokuma Hatalarının Tespiti ve Sınıflandırılması. Yüksek Lisans Tezi, Ege Üniversitesi, Fen Bilimleri Enstitüsü, İzmir.

[5] Yıldız K. 2014. Kumaş Hatalarının Isıl Görüntüleme ve Görüntü İşleme Teknikleri ile Tespit Edilmesi. Doktora Tezi, Marmara Üniversitesi, Fen Bilimleri Enstitüsü, İstanbul.

[6] Agilandeswari V., Anuja J., Elizabeth Dona George. 2014. Fabric quality testing using image processing. International Conference on Information Communication and Embedded Systems (ICICES2014), IEEE, 1-4.

[7] Saklı F., Zitouni B., Jmali M. 2014. Fabric Defects Detecting Using Imagine Processing And Neural Networks. 2014 Information and Communication Technologies Innovation and Application (ICTIA), IEEE, 1-6. 
[8] Liu M., Sun J., Fan Z., Zhang S. 2014. Automatic location and extraction of woven fabric blocks based on Gaussian blur and maximization thought. 2014 International Conference on Mechatronics and Control (ICMC), IEEE, 950-954.

[9] Hanbay K. 2016. Yuvarlak Örgü Makineleri İçin Görüntü işleme Tabanlı Kumaş Hatası Tespit Sistemi. Doktora Tezi, İnönü Üniversitesi, Fen Bilimleri Enstitüsü, Malatya.

[10] Titrek N.G. 2016. Fabric Defect Detection In Frequency Domain Using Fourier Analysis. Yüksek Lisans Tezi, Işık Üniversitesi, Fen Bilimleri Enstitüsü, İstanbul.

[11] Karataş İ., Soyaslan D. 2016. Tekstil Endüstrisinde Yapay Görme ile Hata Tespit Uygulamaları. Mehmet Akif Ersoy Üniversitesi Fen Bilimleri Enstitüsü Dergisi, 7.Özel (Special) 1: 51-57.

[12] Çakır N. 2010. Kot Pantolon Üretiminde Bitim İşlemlerinin ve Farklı Denim Kumaşların Fit Üzerine Etkileri. Yüksek Lisans Tezi, Pamukkale Üniversitesi, Fen Bilimleri Enstitüsü, Denizli.

[13] Tahran M. 2005. Eskitme Yöntemlerinin Denim Mamullerin Performans Özelliklerine Etkisi. Yüksek Lisans Tezi, Dokuz Eylül Üniversitesi, Fen Bilimleri Enstitüsü, İzmir.

[14] TSE. 2005. Dokunmuş Kumaşlar Hata Tarifleri Terimler, TSE, Ankara, Türkiye, TS 471 ISO 8498.

[15] Altuncu M. 2015. Temel Görüntü İşleme Algoritmalarının Gerçek Zamanlı Olarak FPGA İle Gerçeklenmesi. Yüksek Lisans Tezi, Kocaeli Üniversitesi, Fen Bilimleri Enstitüsü, Kocaeli.

[16] Hanbay K., Talu M. 2014. Kumaş Hatalarının Online/Offline Tespit Sistemleri ve Yöntemleri. SAÜ Fen Bilimleri Dergisi, 18 (1): 49-69.

[17] Mahajan P.M., Kolhe S.R., Pati P.M. 2009. A review of automatic fabric defect detection techniques. Advances in Computational Research, 1 (2): 18-29.

[18] Davidson I. 2002. Understanding K-means non-hierarchical clustering. SUNY Albany Technical Report, 2: 2-14.

[19] Yıldız K., Çamurcu Y., Doğan B. 2010. Veri Madenciliğinde Temel Bileşenler Analizi ve Negatifsiz Matris Çarpanlarına Ayırma Tekniklerinin Karşılaştırmalı Analizi. Akademik Bilişim'10, 248.

[20] Pena J.M., Lozano J.A., Larranaga P. 1999. An empirical comparison of four initialization methods for the k-means algorithm. Pattern recognition letters, 20 (10): 1027-1040.

[21] Kaur G., Chhabra A. 2014. Improved J48 classification algorithm for the prediction of diabetes. International Journal of Computer Applications, 98 (22): 13-17.

[22] Coşkun C. 2010. Veri Madenciliği Algoritmaları Karşılaştırılması. Yüksek Lisans Tezi, Dicle Üniversitesi, Fen Bilimleri Enstitüsü, Diyarbakır.

[23] Demirbulut Y.E., Aktaş M.S., Kalıpsız O., Bayracı S. 2017. İstatistiksel ve Makine Öğrenimi Yöntemleriyle Kredi Skorlama. 272-284.

[24] Linear Regression, Yale Universitesi, İstatistik ve Veri Bilimleri Bölümü, Ders Notlar1, http://www.stat.yale.edu/Courses/1997-98/101/linreg.htm (Erişim Tarihi: 07.05.2019).

[25] Hand D.J., Keming Y. 2001. Idiot's Bayes - not so stupid after all?. International statistical review, 69 (3): 385-398.

[26] Ren J., Lee S.D., Chen X., Kao B., Cheng R., Cheung D. 2009. Naive Bayes Classification of Uncertain Data. Data Mining, ICDM'09, 944-949.

[27] Yıldız K. 2014. Kumaş Hatalarının Isı1 Görüntüleme ve Görüntü İşleme Teknikleri İle Tespit Edilmesi. Doktora Tezi, Marmara Üniversitesi, Fen Bilimleri Enstitüsü, İstanbul.

[28] Dutta S., Jha S., Sankaranarayanan S., Tiwari A. 2018. Output range analysis for deep feedforward neural networks. In: NASA Formal Methods Symposium (pp. 121-138), Springer, Cham.

[29] A Quick Primer on Feedforward Neural Networks, https://builtin.com/data-science/feedforwardneural-network-intro (Erişim Tarihi: 23.11.2019).

[30] Ismail N., Syahrir W.M., Zain J.M., Tao H. 2011. Fabric authenticity method using fast Fourier transformation detection. In: International Conference on Electrical, Control and Computer Engineering 2011, IEEE, 233-237.

[31] Gündüz G., Cedimoğlu İ.H. 2019. Derin Öğrenme Algoritmalarını Kullanarak Görüntüden Cinsiyet Tahmini. Sakarya University Journal of Computer and Information Sciences. 2 (1): 917. 